\title{
The set of software tools for prompt assessment of possible pollution of the environment in case of an accident at a radioactively dangerous object
}

\author{
V.P. Kisselev, A.L. Krylov, A.V. Nossov, V.N. Semenov, \\ O.S. Sorokovickova and A.L. Fockin \\ Nuclear Safety Institute of Russian Academy of Sciences, 52 B.Tulskaya St., \\ 115191 Moscow, Russia
}

\begin{abstract}
In case of an accident at a radioactively dangerous object it is necessary to assess promptly possible consequences. Such prompt assessments are almost impossible without appropriate software modelling tools. Nuclear Safety Institute of Russian Academy of Sciences has developed the set of computer programs that enables experts to assess promptly impact of possible accidents on population and environment. The set of software tools includes: models of radionuclides transport in the atmosphere and water objects (rivers, lakes and ponds). It also includes models of assessment of doses of radioactive exposure of humans. The adequate modelling is not possible without accurate electronic maps of the neighborhood of a Nuclear Power Plant (NPP). Thus the electronic maps of neighborhood of all Russian NPP's are supplemented to the set of tools. The necessary data on local population and water objects surrounding NPP's is also included and stored in GIS-based (Geographical Information System) database. That enables numerical modelling to be done within tens of minutes at most. The GIS enables use of spatial data on fallout of radioactive substances from the model of atmospheric transport to be used as input data for modelling of transport in water objects.
\end{abstract}

\section{INTRODUCTION}

In case of an accident at a radioactively dangerous object (nuclear power plants (NPP), sites for decommissioning of nuclear submarines, etc) it is necessary to assess promptly possible consequences extent of contaminants spreading for decision-making on protective actions (if necessary). Such prompt assessments are almost impossible without appropriate software modelling tools. Nuclear Safety Institute of Russian Academy of Sciences have developed the set of computer programs that enables experts of Technical Support Center of Crisis Center of "Rosenergoatom" to assess promptly impact of possible accidents on population and environment (“Rosenergoatom” manage all 10 Russian NPP's).

The set of software tools includes: models of radioactivity transport in the atmosphere and water objects (rivers, lakes and ponds). It also includes models of assessment of doses of radioactive exposure of humans.

The adequate modelling is not possible without accurate electronic maps of the neighborhood of a NPP. Thus the electronic maps of all Russian NPP's vicinities are supplemented to the set of tools. The necessary data on local population and water objects surrounding NPP's is also included and stored in GIS-based (Geographical Information System) database. That enables numerical modelling to be done within minutes or tens of minutes at most.

\section{ATMOSPHERIC MODELLING}

The most of major accidents in the past that have resulted in the release of radioactive substances to the environment have been followed by release of radioactivity to the atmosphere. Transport of 
radioactivity in the air can be very fast. Thus in the case of an accident it is necessary to assess promptly areas and settlements in danger in order to take protective measures in time. This assessment can be done by modelling of transport of radioactivity in the atmosphere with the use of computer system "Nostradamus" [1, 2] developed with the support of Russian Fund of Fundamental Research (project no. 06-08-01501-a).

The "Nostradamus" is based on the mesoscale stochastic (based on Monte-Carlo method) Lagrangian trajectory model of radioactive admixture transport, which enables real-time modelling for distances of hundreds of kilometers. The model takes into account dry deposition of an admixture and fallouts due to precipitations.

In trajectory models simultaneous movement of many «points» describes migration of an admixture. The total amount of discharged radioactivity is divided between the "points" at the beginning of modelling. Every point moves with the speed of the wind at its location. To model diffusion of admixture a random shift of the trajectory is applied at each time step. The magnitude of this shift depends on coefficient of turbulent dispersion. To ensure smoothness of fields of concentrations, every "point" is assumed to be a moving "cloud" of finite size with total amount of radioactivity equal to the amount of radioactivity assigned to the "point". The size of a cloud grows in time with the rate proportional to the square root of diffusion coefficient. So the concentration of an admixture at any node of the computational grid is the sum of contributions of all "clouds".

The Lagrangian model has the number of advantages over widely used traditional Gaussian models. It enables modelling of radioactivity transport over hundreds of kilometers, enables to take into account precipitation, heterogeneity and changeability of velocity field, influence of the relief on the dispersion.

The validation of the model have been done by analysis of more than 800 comparisons of modeled values and values observed during full-scale experiments [3-5]. The observed data used for modelling cover the wide range of parameters:

- Wind velocity from 0,5 to $15 \mathrm{~m} / \mathrm{s}$

- Source altitude from 0 to $150 \mathrm{~m}$

- Distance of radionuclide transport from 0,5 to $400 \mathrm{~km}$

- Atmospheric stability from stable to unstable

The validation have shown that good accordance of modelling results with observed data for the Lagrangian model can be achieved in wider range of input data than for Gaussian models.

The necessary input data for "Nostradamus" are:

- Meteorological data;

- Data on source of the radioactive substances;

- Electronic maps of the region of modelling containing topographic data and distribution of population;

- Type of landscape and data on surface roughness.

The "Nostradamus" calculates for every node of the calculation grid for any moment of time:

- Concentration and temporal integral of concentration of every radionuclide;

- Fallout density of every radionuclide;

- The rate of exposure (and summary doses of exposure) of every organ of human body from every radionuclide separately (and summary dose from all radionuclides).

It is necessary to mention that "Nostradamus" can be used only for barotropic atmosphere. It cannot be used for modelling of radioactivity transport in special meteorological conditions: atmospheric fronts, breeze circulation, etc.

These assessments can be used for decision-making on population protection and as input data for models of migration of radioactive substances in water objects. It also necessary to mention that the "Nostradamus" can be used not only for decision support in case of an accident. It also can be used for radiation safety analysis. 


\section{WATER MODELLING}

It is known that rivers can transport contaminants at long distances (hundreds and even thousands of kilometers). Radioactive contamination of rivers, lakes, ponds, flood-plains and irrigated territories can result in radioactive exposure of population due to use of water objects for recreation and fishing, consumption of contaminated water and fish, consumption of meat and milk from cattle that was watered by contaminated water or fed on contaminated pastures, consumption of vegetables cultivated at contaminated flood-plains or irrigated areas.

Radioactive substances can be accumulated in bed sediments of the water objects and in river basins and thus to be the source of radioactive exposure of population during tens and hundreds of years after termination of operation of a NPP or another object of nuclear fuel cycle. That's why it is very important to model migration and accumulation of radioactivity in rivers, lakes and ponds. For modelling of transport and accumulation in water objects of radioactive substances the computer system "Cassandra" [6] can be used.

The "Cassandra" is based on the two-compartmental (water and bed sediments) model taking into account all important processes: inflow of radioactivity from different sources; radioactive decay; advection; dispersion; radioactivity exchange processes between water mass, bed sediments and suspended particles; mass-exchange between main river flow and underflow; technological water losses; diffusion of radioactivity within the bed sediments.

The main suggestions of the model are as follows:

- Rate of exchange by radioactive substances between water and bottom sediments is proportional to the concentration of radioactivity in the liquid and the solid phases;

- The processes of sorption and desorption of radioactivity by the solid phase is considered instantaneous, equilibrium and obeying the linear isotherm with the invariable distribution coefficient;

- The exchange between the river bottom and the water mass proceeds within an equally-accessible upper layer of bottom sediments (effective layer);

- Radioactive substances are transferred in rivers by water flow and are dispersed over the water volume due to longitudinal turbulent dispersion. In rivers the substances are distributed uniformly over the river section, and only the longitudinal component of convective dispersion is taken into account.

"Cassandra" enables one to take into account all important ways of contamination of water objects: direct discharge of contaminated water, atmospheric fallouts, entry of contaminated subsoil waters, contaminated tributaries, wash-out from contaminated river-basin, etc.

The basic equations describing the transport of radionuclides along the river is as follows:

$$
\left\{\begin{aligned}
& \frac{\partial\left(A C_{1}(x, t)\right)}{\partial t}+\frac{\partial}{\partial x}\left(Q C_{1}-\mathrm{D}_{\mathrm{L}} A \frac{\partial C_{1}}{\partial x}\right)=-\lambda A C_{1}-\frac{A C_{1} U \alpha_{T 1}}{H}+\frac{A C_{2} \vartheta \alpha_{T 2}}{H} \\
&+\frac{A \beta}{H} *\left(\alpha_{P 2} C_{2}-\alpha_{P 1} C_{1}\right)-\frac{A \xi \alpha_{P 1} C_{1}}{H}+F(x, t) \\
& \frac{\partial C_{2}(x, t)}{\partial t}=-\lambda C_{2}+\frac{C_{1} U \alpha_{T 1}}{h}-\frac{\vartheta C_{2} \alpha_{T 2}}{h}-\frac{\beta}{h}\left(\alpha_{P 2} C_{2}-\alpha_{P 1} C_{1}\right)-\frac{W_{c} C_{2} \alpha_{T 2}}{h}-\frac{\gamma \alpha_{P 2} C_{2}}{h}
\end{aligned}\right.
$$

where: ' $\mathrm{t}$ ' is the time (s); ' $\mathrm{x}$ ' is the coordinate along the river channel $(\mathrm{m})$; ' $\mathrm{C}_{1}$ ' and ' $\mathrm{C}_{2}$ ' are total concentrations in water and bottom sediments, respectively $\left(\mathrm{Bq} / \mathrm{m}^{3}\right)$; ' $\lambda$ ' is the radioactive decay constant $(1 / \mathrm{s})$; ' $\mathrm{A}$ ' is the river section area $\left(\mathrm{m}^{2}\right)$; " $\mathrm{H}$ " is the average depth $(\mathrm{m})$; ' $\mathrm{Q}$ ' is the flow rate of running water $\left(\mathrm{m}^{3} / \mathrm{s}\right)$; ' $\mathrm{D}_{\mathrm{L}}$ ' is the longitudinal dispersion coefficient $\left(\mathrm{m}^{2} / \mathrm{s}\right)$; ' $\mathrm{F}$ ' describes radionuclide inflow sources $\left(\mathrm{Bq} /\left(\mathrm{m}^{*} \mathrm{~s}\right)\right)$; ' $\mathrm{h}$ ' is the thickness of effective layer $(\mathrm{m})$; ' $\beta$ ' is the coefficient of diffusive mass exchange of radionuclides between water mass and bottom sediments $(\mathrm{m} / \mathrm{s})$; ' $U$ ' is the average precipitation rate of suspended particles $(\mathrm{m} / \mathrm{s}) ;$ ' $\alpha_{\mathrm{T} 1}$ ' is the fraction of a radionuclide sorbed by suspended particles (dimensionless unit); ' $\alpha_{\mathrm{T} 2}$ ' is the fraction of a radionuclide sorbed by the solid 


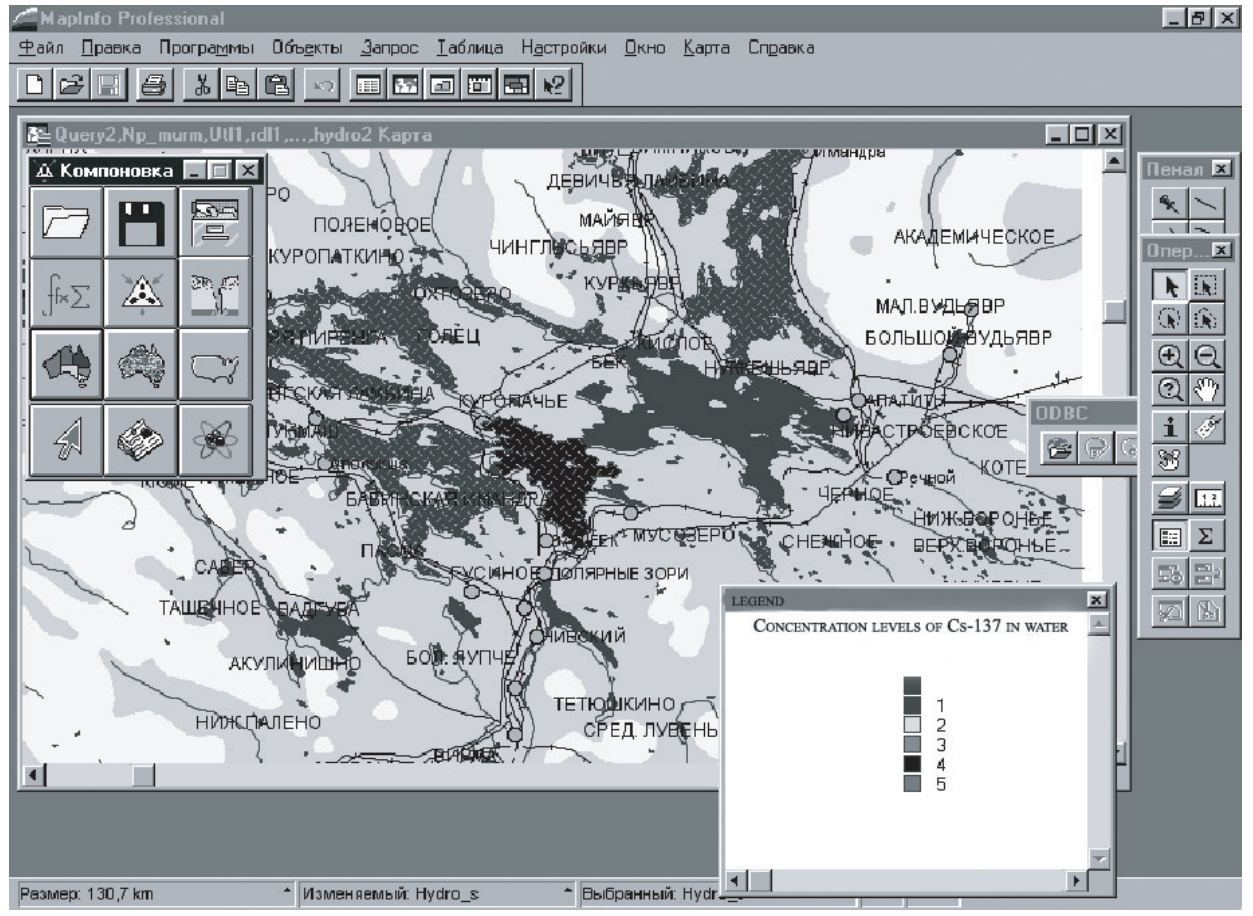

Figure 1. Water objects colored depending on their contamination.

phase of the effective layer of bottom sediments (dimensionless unit); ' $\alpha_{\mathrm{p} 1}$ ' and ' $\alpha_{\mathrm{p} 2}$ ' are the fractions of a radionuclide being in the dissolved state in water mass and in the effective layer of bottom sediments, respectively (dimensionless units); ' $\gamma$ ' is the mass exchange coefficient of a radionuclide contained in interstitial water between the effective layer of bottom sediments and the bottom stratum ( $\mathrm{m} / \mathrm{s})$; ' $\vartheta$ ' is a radionuclide mass exchange coefficient due to process of stirring-up (erosion) of contaminated bottom sediments $(\mathrm{m} / \mathrm{s})$, ' $\zeta$ ' is the mass-exchange coefficient of dissolved-in-water radionuclides between the main stream and the underflow $(\mathrm{m} / \mathrm{s}) ; W_{c}-$ is the rate of sedimentation $(\mathrm{m} / \mathrm{s})$.

The values of ' $\alpha_{\mathrm{T} 1}$ ', ' $\alpha_{\mathrm{T} 2}$,', ' $\alpha_{\mathrm{p} 1}$ ' and ' $\alpha_{\mathrm{p} 2}$ ' determining the radionuclide fractions sorbed and dissolved states can be found from the following expressions:

$$
\alpha_{p 1}=\frac{1}{1+S_{1} k_{d 1}}, \quad \alpha_{p 2}=\frac{1}{1+m k_{d 2}}, \quad \alpha_{T 1}=\frac{S_{1} k_{d 1}}{1+S_{1} k_{d 1}}, \quad \alpha_{T 2}=\frac{m k_{d 2}}{1+m k_{d 2}} ;
$$

where: ' $\mathrm{k}_{\mathrm{d} 1}$ ' is the distribution coefficient of a radionuclide in the water-suspension system, $\mathrm{m}^{3} / \mathrm{kg}$; ' $\mathrm{k}_{\mathrm{d} 2}$ ' is the distribution coefficient of a radionuclide between interstitial water and the solid phase of the effective layer of bottom sediments, $\mathrm{m}^{3} / \mathrm{kg}$; ' $\mathrm{S} 1$ ' is water turbidity, $\mathrm{kg} / \mathrm{m}^{3}$; ' $\mathrm{m}$ ' is the volume weight of the effective layer of bottom sediments, $\mathrm{kg} / \mathrm{m}^{3}$.

The equations for lakes or ponds are similar:

$$
\left\{\begin{array}{l}
\frac{\partial C_{1}}{\partial t}=-\lambda C_{1}-\frac{C_{1} U \alpha_{T 1}}{H}+\frac{C_{2} \vartheta \alpha_{T 2}}{H}+\frac{\beta}{H} *\left(\alpha_{P 2} C_{2}-\alpha_{P 1} C_{1}\right)-\frac{Q_{L}}{V} C_{1}-\frac{Q_{f}}{V} C_{1} \alpha_{P 1}+F \\
\frac{\partial C_{2}}{\partial t}=-\lambda C_{2}+\frac{C_{1} U \alpha_{T b}}{h}-\frac{C_{2} \vartheta \alpha_{T 2}}{h}-\frac{\beta}{h}\left(\alpha_{P 2} C_{2}-\alpha_{P 1} C_{1}\right)-\frac{W_{c} C_{2} \alpha_{T 2}}{h}-\frac{\psi \alpha_{P 2} C_{2}}{h}
\end{array}\right.
$$


where: $Q_{L}$ - is the intensity water flow out of the water object summed with technological and other water losses $\left(\mathrm{m}^{3} / \mathrm{s}\right) ; Q_{f}$ - is the intensity of water filtration through the layer of bottom sediments $\left(\mathrm{m}^{3} / \mathrm{s}\right) ; \psi-$ is the factor of diffusive mass-exchange between the effective layer and underlying layers. The rest of variables are described above.

The modelling results are used for assessment of doses from waterways (mentioned above) of exposure of population and can be used for decision-making on limitation of the water use and/or other protection measures. The ration and water-use habits of every group of population can be taken into account.

The integration of computer models on the base of GIS enables use of spatial data on fallout of radioactive substances from "Nostradamus" to be used as input data for modelling contamination of water objects by "Cassandra".

The "Cassandra" was validated by comparison of modelling results with observed data on contamination resulted from major sources of radioactive contamination the catastrophe at Chernobyl NPP [7] and operation of "Mayak" plant [8].

The model for lakes and ponds was validated with the use of observed data on contamination of cooling pond of the Chernobyl NPP and some other lakes contaminated in the result of atmospheric fallouts of radionuclides from the NPP.

The model for rivers was validated with the use observed data on contamination of the Techa River (more than $200 \mathrm{~km}$ long). This river and its basin were heavily contaminated by long-living radionuclides during decades of operation of "Mayak" plant.

The validation has shown good accordance of observed and modelling values of concentrations of radioactive contaminants in water and bed sediments.

\section{CONCLUSION}

The software tools described above have modern user-friendly interface. The results of modelling can be presented as table, graphs or electronic maps.

All necessary calculations (atmospheric propagation, migration in water objects, exposure of humans) can be done on personal computer in minutes or tens minutes at most if all necessary data are present. The data necessary for modelling that can be collected beforehand should be collected beforehand. That's why the data on Russian NPP's (topography, hydrology, data on local population, data on NPP's itself) had been collected and stored in the GIS database.

It enables the use of the set of software tool for decision support in case of an accident on a radioactively dangerous object. Experts of Technical Support Center (located in Nuclear Safety Institute of Russian Academy of Sciences) of Crisis Center of «Rosenergoatom» in the course of regular trainings at Russian NPP's successfully use the set of computer models.

\section{References}

[1] Arutunjan R.V., Belickov V.V., Belickova G.V., Sorokovickova O.S. et al., New effective numerical methods of modelling of migration of radioactive substances in the atmosphere and its practical use, Izvestia of Russian Academy of Sciences (Energy) 4 (1995).

[2] Semenov V.N., Arutunjan R.V., Kisselev V.P., Fockin A.L. et al., Izvestia of Russian Academy of Sciences (Energy) 4 (1995).

[3] Pasler-Sauer J., Comparative calculations and validation studies with atmospheric dispersion models. //Report KfK 4164, November 1986,130.

[4] Rolf Lange. Journal of applied meteorology, 17, 3 (1978).

[5] Grisenko A.I., Belov N.S., Semenov V.N. and Sorokovickova O.S., The Unique Experiments on the Assessment of Accident Consequences at the Gas Transport Systems. Society for Risk Analysis - EUROPE, Stockholm 1997, pp. 724-729. 
[6] Krylov A.L., Nossov A.V., Kisselev V.P., Zhilina N.I. and Kazakov S.V., Izvestia of Russian Academy of Sciences (Energy) 3 (2004).

[7] Kazakov S., Kisselev V., Krylov A. and Zhilina N., "Informational and modelling computer system for prediction estimation and analysis of radioactive contamination of surface water objects", In Proceedings the Second International Conference "River Basin Management II" Las-Palmas of Gran Canaria, Spain, 2003, edited by Brebbia C.A. (WIT Press, UK, 2003), pp. 289-298.

[8] Krylov A.L., Nossov A.V., Kryshev A.I., Kryshev I.I. and Kisselev V.P., Meteorology and Hydrology 7 (2007). 